\title{
EDITORIAL
}

\section{In appreciation of Theodor Escherich}

\author{
This year is the 150th anniversary of the birth of Theodor Escherich, the German physician \\ who discovered Escherichia coli. Jörg Hacker and Gabriele Blum-Oehler reflect on the life of \\ Escherich and his contribution to microbiology.
}

Since its discovery in the late nineteenth century, Escherichia coli has arguably become the best understood cellular life form, primarily because of its role as a model organism and the molecular biological 'workhorse' of numerous laboratories around the world. Moreover, E. coli is not only a harmless intestinal inhabitant, but is also a highly versatile pathogen that contributes significantly to the burden of infectious disease.

Theodor Escherich, the paediatrician who discovered E. coli, was born in Germany in 1857, and began his medical education at the University of Würzburg. In 1884, he moved to Munich and began a series of studies that examined the impact of intestinal bacteria on the physiology and pathology of the gastrointestinal tract. Robert Koch's student, Wilhelm Frobenius, introduced Escherich to pure culture and bacterial-characterization techniques, and it was during this period that he devoted himself to bacteriology and introduced a new method for evaluating the faeces of infants. In 1885, Escherich presented the lecture "The intestinal bacteria of the neonate and infant" to the Society of Morphology and Physiology, in which he described the morphology and properties of a bacterial population - termed the "bacterium coli commune" - that he had observed in the lower sections of the gut ${ }^{1}$. In 1886, after 18 months of intensive research, he published his 'habilitation' thesis entitled "The intestinal bacteria of neonates and their relationship to the physiology of digestion", a body of work that established him as one of the leading bacteriologists of his era. Throughout his career, he published numerous articles about the morphology, cultivation and physiology of various intestinal bacteria. In addition to this work, Escherich was also devoted to the improvement of child care and reducing the high levels of infant mortality that were prevalent at that time.

It is likely that Theodor Escherich would have been hugely impressed by the pivotal role of $E$. coli in the development of modern molecular biology. The importance of this organism is visible in the fact that several Nobel prizes have been awarded to scientists for their work on different aspects of $E$. coli biology. These include Joshua Lederberg for his discoveries concerning genetic recombination and the organization of the genetic material of bacteria (1958); François Jacob, André Lwoff and Jacques Monod for their discoveries on the genetic control of enzyme and virus synthesis (1965); and Max Delbrück, Alfred Hershey and Salvador Luria for their discoveries relating to the replication mechanism and the genetic structure of viruses (1969).

In honour of Theodor Escherich's life, his discovery of E. coli and the 150th anniversary of his birth, a conference supported by FEMS, EMBO and the German Academy of Sciences Leopoldina was recently held in Germany. The conference, entitled " $E$. coli - facets of a versatile pathogen", focused solely on this fascinating bacterium. Topics included the evolution of the organism's different phenotypes (ranging from harmless commensals to intestinal and extra-intestinal E. coli (ExPEC) pathotypes) $)^{2}$, its virulence mechanisms, genomics, gene regulation and host-pathogen interactions, and these were all the focus of extensive discussion. A recurrent theme throughout the meeting was the question of why certain isolates of $E$. coli are pathogenic and others are commensals. Comparative genome analyses of pathogenic and nonpathogenic E. coli variants have shown that the E. coli 'pan-genome' is considerably larger than expected and, perhaps not surprisingly, the ability to acquire various virulence-associated genes distinguishes pathogenic E. coli from commensal isolates ${ }^{3}$. Indeed, the frontier between commensalism and ExPEC pathogenicity is fluent and the definition of a pathogen has to be strainspecific. Despite years of research, new virulence-associated genes from $E$. coli variants continue to be discovered, especially colonization factors that contribute to the infectious process. Furthermore, the interaction between E. coli and the host, and the contribution of biofilms, are still ongoing questions of important interest.

So, despite the 122 years that have passed since Theodor Escherich first described E. coli, and the staggering amount of research that has been devoted to this fascinating microorganism, it is illuminating to learn that there are still many aspects of its biology that remain to be discovered. Here's to the next 122 years!

\footnotetext{
Escherich, T. Die darmbakterien des neugeborenen und säuglings. Fortschr. Med. 3, 515-522; 547-554 (1885).

2. Kaper, J. B. et al. Pathogenic Escherichia coli. Nature Rev. Microbiol. 2, 123-140 (2004).

3. Brzuszkiewicz, E. et al. How to become a uropathogen: comparative genomic analysis of extraintestinal pathogenic Escherichia coli strains. Proc. Natl Acad. Sci. USA 103, 12879-12884 (2006).
} 